\title{
Epilepsy care guidelines for low- and middle- income countries: From WHO mental health GAP to national programs
}

\author{
Juri Katchanov ${ }^{1,2}$ and Gretchen L Birbeck ${ }^{3,4^{*}}$
}

\begin{abstract}
In 2011, the World Health Organization's (WHO) mental health Gap Action Programme (mhGAP) released evidence-based epilepsy-care guidelines for use in low and middle income countries (LAMICs). From a geographical, sociocultural, and political perspective, LAMICs represent a heterogenous group with significant differences in the epidemiology, etiology, and perceptions of epilepsy. Successful implementation of the guidelines requires local adaptation for use within individual countries. For effective implementation and sustainability, the sense of ownership and empowerment must be transferred from the global health authorities to the local people. Sociocultural and financial barriers that impede the implementation of the guidelines should be identified and ameliorated. Impact assessment and program revisions should be planned and a budget allocated to them. If effectively implemented, as intended, at the primary-care level, the mhGAP guidelines have the potential to facilitate a substantial reduction in the epilepsy treatment gap and improve the quality of epilepsy care in resource-limited settings.
\end{abstract}

Keywords: Non-physician healthcare worker, clinical officer, variations in care, treatment gap

\section{Review}

\section{Introduction}

Epilepsy is a major global healthcare issue. An estimated 70 million people worldwide live with epilepsy [1,2], most of whom remain untreated [3]. To improve epilepsy-care services, most developed countries adopted national guidelines at least a decade ago, with these being

\footnotetext{
* Correspondence: birbeck@msu.edu

${ }^{3}$ Michigan State University, International Neurologic and Psychiatric

Epidemiology Program, East Lansing, Michigan, USA

Full list of author information is available at the end of the article
}

regularly updated [4-6]. Whenever possible, such guidelines are evidence-based, relying upon the body of evidence for best care practices in high-income, resource-rich countries with predominantly moderate climates. However, $80 \%$ of people with epilepsy (PWE) live in so-called 'developing', low-income, or resource-poor countries in tropical or subtropical regions[1]. For many reasons including resource restrictions, simply adopting healthcare guidelines created for higher-resourced areas and using these in resource-limited settings is neither appropriate nor feasible [7]. Unfortunately, such settings generally lack sufficient neurologic expertise and/or advocacy for the development and implementation of epilepsy-care guidelines. The World Health Organization (WHO) recently released evidence-based, epilepsy-care guidelines appropriate for use in resource-limited, tropical settings $[8,9]$. Implementation of the WHO mental health Gap Action Programme (mhGAP) guidelines will require local adaptation for use within individual countries, but if effectively implemented as intended at the primary-care level, the mhGAP guidelines could facilitate a substantial reduction in the epilepsy treatment gap and improve the quality of care received by PWE in resourcelimited settings. Effective guidelines require local adaptation, implementation, impact assessment, and program revision. The challenges to these important processes are substantial.

\section{World Health Organization Mental Health Gap Action Programme guideline development}

Low-income and high-income regions differ substantially in terms of the underlying etiologies of epilepsy, the expertise of the healthcare personnel, and the diagnostic capacity, treatment options, and cultural perception of the disorder (Table 1). Guidelines for use in the resource-poor environments must address factors specific for the clinical and sociocultural setting (Table 2). Valid guidelines are of paramount importance for low-income tropical regions as

\section{() Biomed Central}


Table 1 Critical differences affecting health and health care in high-income versus low-income and middle-income countries $[19,23]$

\begin{tabular}{|c|c|c|}
\hline & High-income countries & Low-income and middle-income countries \\
\hline $\begin{array}{l}\text { Gross national income } \\
\text { per capita }\end{array}$ & High $\geq$ US\$9,386; upper middle US\$3,036 to $\$ 9,385$ & Low $\leq$ US\$765 or lower; middle US\$766 to $\$ 3,035$ \\
\hline Access to health care & $\begin{array}{l}\text { Initial access usually through primary care with } \\
\text { established referral networks, which may include high } \\
\text { indirect costs }\end{array}$ & $\begin{array}{l}\text { Limited to very basic primary care especially in rural areas and/or } \\
\text { established referral networks, which invariably include high } \\
\text { indirect costs }\end{array}$ \\
\hline Healthcare funding & $\begin{array}{l}\text { National programs, private insurance, out-of-pocket } \\
\text { expenses }\end{array}$ & $\begin{array}{l}\text { Often ill-funded, may rely on donors/volunteering services. } \\
\text { Indirect costs and informal payments can represent major } \\
\text { barriers to care }\end{array}$ \\
\hline $\begin{array}{l}\text { Common epilepsy } \\
\text { etiologies }\end{array}$ & Neoplastic, cerebrovascular & (Post-)infectious, antenatal, post-traumatic \\
\hline HIV prevalence & Low & Can be moderate to high \\
\hline $\begin{array}{l}\text { Cultural perception of } \\
\text { seizures }\end{array}$ & Biomedical model & $\begin{array}{l}\text { Traditional medicine, spiritual approach; contagion beliefs } \\
\text { common }\end{array}$ \\
\hline $\begin{array}{l}\text { Socio-cultural attitudes } \\
\text { towards epilepsy }\end{array}$ & $\begin{array}{l}\text { Neutral public perception or at least social } \\
\text { presentation of neutrality }\end{array}$ & $\begin{array}{l}\text { Overt negative public perception, stigmatization, and } \\
\text { discrimination common }\end{array}$ \\
\hline
\end{tabular}

the mortality associated with epilepsy in such regions may be relatively high even when there is treatment available [10], and the treatment gap remains vast, with less than $20 \%$ of people with active epilepsy in most developing countries receiving treatment [11].

Guidelines developed in high-income countries are likely to be inappropriate for use in LAMICs [7]. In general, the transferability of evidence derived from studies conducted in high- income countries to LAMICS is dubious $[7,12,13]$. Differences in patient populations and healthcare systems are so prominent that the evidence may not be valid $[7,14]$; hence, the development of guidelines specifically crafted for resource-limited settings is the best strategy.

In 1977, the WHO, in collaboration with the International League against Epilepsy and the International Bureau for Epilepsy, launched the Global Campaign Against

Epilepsy to improve the care of PWE in resource-poor countries [15]. In 2008, WHO began development of evidence-based guidelines for epilepsy and seizure care in LAMICs [8,16], and these guidelines were released in 2011.

\section{Local adaptation of the guidelines}

The clinical care algorithms provided in the mhGAP were developed for use in a wide range of possible low-income and middle- income settings, and therefore must be adapted to local resources and needs, especially if the guidelines are to be used by the non-physician healthcare workers who provide most primary healthcare services in such settings. From the geographical, sociocultural, and political viewpoints, countries previously termed 'developing' represent a markedly heterogenous group. The epilepsy burden is different in Asia, Latin America, and sub-Saharan Africa [17], and even within one area, such as sub-Saharan Africa, there are significant variations in the epidemiology, etiologies, and perceptions of epilepsy in different geographical regions and communities [18]. The process of adaption also offers the opportunity to further foster a sense of ownership and empowerment among local health authorities [19].

The most feasible and cost-effective way to deliver epilepsy care in LAMICs is through the use of inexpensive antiepileptic drugs (AEDs) delivered by non-physician healthcare workers at the primary-care level [20]. Clinical case definitions for epileptic seizures and epilepsy used for guideline application must consider the limited neurologic expertise of primary-care providers, lack of diagnostic options, and the local syntactic/semantic language used for describing seizure symptoms, as well as the time frame

Table 2 Realities and requirements for guidelines for low-income and middle- income countries

\begin{tabular}{ll}
\hline Reality & Requirement \\
\hline $\begin{array}{l}\text { Care is largely provided by non-physician healthcare workers } \\
\text { Limited access to medication }\end{array}$ & $\begin{array}{l}\text { Clear case definition of epileptic seizures and simple algorithms tailored for the local } \\
\text { circumstances }\end{array}$ \\
\hline Indirect costs as a barrier to care-seeking and adherence & $\begin{array}{l}\text { Guidelines recommending those medications that can be accessed } \\
\text { as possible }\end{array}$ \\
\hline High prevalence of infectious causes & $\begin{array}{l}\text { Incorporate into guidelines testing/treating of common conditions such as HIV, } \\
\text { neurotuberculosis, and parasitosis. Refer to existing treatment guidelines whenever } \\
\text { possible unless comorbid conditions require care that differs from national } \\
\text { guidelines }\end{array}$ \\
\hline
\end{tabular}


of the symptoms [21]. The mhGAP guidelines recognize that in LAMICs, seizures are often caused by acute central nervous system (CNS) infection or metabolic disorders. Furthermore, epilepsy can be the first presentation of a sub-acute or chronic CNS condition that might be amenable to treatment in resource-poor environment [20]. Hence, local adaptation of mhGAP guidelines must consider the local epidemiology of potential underlying seizure etiologies [20,22].

Local adaptation must also address any special circumstances within a specific country. For example, where HIV rates are high, a significant proportion of PWE can be expected to also have co-morbid HIV infection. If the available AEDs are limited to enzyme-inducing agents, potential interactions between AEDs and antiretroviral medications must be considered, and treatment options appropriate for dual therapy must be made available $[23,24]$. Guidelines for epilepsy care in resource-limited settings by non-physician healthcare workers must also specifically address injury prevention and, if applicable, fears of contagion [10]. The adapted content of such programs must be directed by local practices, injury risk factors, and beliefs.
The development of national programs in LAMIC should be paralleled by clinical research increasing our knowledge of epilepsy beyond high-income regions. Such research would facilitate the development of a new multidimensional classification of epilepsy applicable to a wide range of settings including LAMIC [25,26].

\section{Implementing guidelines in low-income and middle-} income countries

Passive dissemination of guidelines is on its own insufficient to ensure appropriate uptake of recommendations [27]. Sociocultural and financial barriers impede the implementation of guidelines in all healthcare settings. Within LAMICs, strong advocacy for guideline adoption by health authorities at the national, provincial, district, and institutional levels are required [27]. Barriers at the patient, healthcare worker and macro level threaten the implementation of guidelines [23]. True advocacy requires that local healthcare authorities prioritize epilepsy care sufficiently highly to guarantee that the basic materials and training required to adhere to the guidelines are provided to healthcare workers at every level of care for which they are intended. If care equity is to be

Clear case definitions of epileptic seizures and epilepsy, tailored for use by non-physician healthcare workers

User-friendly guidelines adapted for local environment, based on local diagnostic capacity and with input from local experts and stakeholders Active dissemination of guidelines with workshops appropriate for resourcelow setting Implementation of the guidelines within the framework of the existing healthcare delivery system. Should include using the guidelines for testing for treatable causes of epilepsy

Meticulous evaluation of guidelines which include local researchers and provides feedback to the local stakeholders as well as the WHO 
achieved, special attention must be focused on the implementation of the guidelines in poorer rural areas, because residency in a rural region is an independent risk factor for poor access to treatment [3].

Particularly in rural areas, 'buy-in' from local stakeholders is of paramount importance. This requires seeking active input from local communities in developing national priorities and programs at an early stage. Such stakeholders should also be involved the program-evaluation process. Important local stakeholders may include individuals such as traditional healers, who are often the de facto care providers for PWE [28]. Whenever possible, collaborations that do not compromise patient care and safety should be sought. Provoking a culture clash between traditional and 'western-type' medicine is unlikely to benefit the patient with epilepsy.

\section{Impact assessment}

As guidelines are being implemented, program evaluations to assess their operational performance in clinical practice and their effects on care quality should be concurrently planned and budgeted [29]. As in more medically developed countries [30], low-income countries need valid quality indicators for epilepsy care that can adequately assess the effects of guideline implementation. It may be possible to develop such quality indicators even with basic health records in some LAMIC institutions [31]. Before initial implementation, plans should be discussed for updating guidelines as needed and revising them based upon the findings of the impact assessment. Special consideration should also be given to any potential unintended consequences of the guidelines. For example, if a guideline refers to additional diagnostic studies, is it possible for primary-care workers to delay necessary seizure treatment while waiting for an electroencephalogram or neuroimaging, when access to such studies are limited and the logistics of study acquisition are challenging?

\section{Conclusion}

The mhGAP guidelines need to be adapted for countryspecific use in LAMICs. These baseline recommendations can facilitate the development of national guidelines and the establishment of national epilepsy programs tailored to the existing healthcare setting. The locally relevant guidelines should then be critically evaluated and amended if necessary, based on the results of the assessment (Figure 1). Evaluations are needed to ensure that the guidelines are practical, evidence-based. and cost-effective [32,33]. Training resources (including sample pathways and video training) adapted for local primary-care settings should be expanded to facilitate the acceptance and successful implementation of the guidelines [9]. The implementation of epilepsy guidelines could result in a decrease in the burden of epilepsy worldwide [16].

\section{Abbreviations}

AED: antiepileptic drug; CNS: central nervous system; LAMIC: Iow- and middle- income countries; mhGAP: mental health Gap Action Programme; PWE: people with epilepsy; WHO: World Health Organization.

\section{Author details}

'Department of Infectious Diseases and Gastroenterology, Auguste-ViktoriaKrankenhaus, Berlin, Germany. ${ }^{2}$ Queen Elizabeth Central Hospital, Blantyre, Malawi. ${ }^{3}$ Michigan State University, International Neurologic and Psychiatric Epidemiology Program, East Lansing, Michigan, USA. ${ }^{4}$ Chikankata Hospital, Epilepsy Care Team, Mazabuka, Zambia.

\section{Authors' contributions}

GLB and JK co-conceived the idea for this commentary. JK sought relevant literature for this manuscript and wrote the first draft of the manuscript. GLB provided critical input and edits for the final version. Both authors approved the final manuscript.

\section{Authors' Information}

GLB and JK are neurologists who trained in academic centers in the developed world, but they have extensive experience providing epilepsy care in tropical, resource-limited settings.

\section{Competing interests}

JK declares no conflict of interest or competing interests. GB served as an advisor to the World Health Organization and participated in the development of the mental health Gap Action Programme guidelines and the National Guidelines for Epilepsy Care adopted by the Neurologic and Psychiatric Society of Zambia. She has received research funds for epilepsyrelated work from the US National Institute of Health.

Received: 10 July 2012 Accepted: 24 September 2012

Published: 24 September 2012

\section{References}

1. Ngugi AK, Bottomley C, Kleinschmidt I, Sander JW, Newton CR: Estimation of the burden of active and life-time epilepsy: a meta-analytic approach. Epilepsia 2010, 51(5):883-890.

2. Ngugi AK, Kariuki SM, Bottomley C, Kleinschmidt I, Sander JW, Newton CR: Incidence of epilepsy: a systematic review and meta-analysis. Neurology 2011, 77(10):1005-1012.

3. Meyer AC, Dua T, Ma J, Saxena S, Birbeck G: Global disparities in the epilepsy treatment gap: a systematic review. Bull World Health Organ 2010, 88(4):260-266.

4. Gumnit RJ, Walczak TS: Guidelines for essential services, personnel, and facilities in specialized epilepsy centers in the United States. Epilepsia 2001, 42(6):804-814.

5. Labiner DM, Bagic Al, Herman ST, Fountain NB, Walczak TS, Gumnit RJ: Essential services, personnel, and facilities in specialized epilepsy centers-revised 2010 guidelines. Epilepsia 2010, 51(11):2322-2333.

6. Nunes VD, Sawyer L, Neilson J, Sarri G, Cross JH: Diagnosis and management of the epilepsies in adults and children: summary of updated NICE guidance. Bmi 2012, 344:e281.

7. Ehrhardt S, Meyer CG: Transfer of evidence-based medical guidelines to low- and middle-income countries. Trop Med Int Health 2012.

8. WHO: mhGAP: Scaling up care for mental, neurological and substance use disorders. 2011 [http://wwwwhoint/mental_health/ mhgap_final_englishpdf].

9. WHO: mhGAP Newsletter. 2011 [http://wwwhoint/mental_health/ mhGAP_nl_jun2011_enpdf].

10. Birbeck $G$, Hesdorffer $D$ : The geography of epilepsy: a fatal disease in resource-poor settings. Neurology 2011, 77(2):96-97.

11. Mbuba CK, Ngugi AK, Newton CR, Carter JA: The epilepsy treatment gap in developing countries: a systematic review of the magnitude, causes, and intervention strategies. Epilepsia 2008, 49(9):1491-1503. 
12. Chinnock P, Siegfried N, Clarke M: Is evidence-based medicine relevant to the developing world? PLoS Med 2005, 2(5):e107.

13. Schunemann HJ, Fretheim A, Oxman AD: Improving the use of research evidence in guideline development: 13. Applicability, transferability and adaptation. Health Res Policy Syst 2006, 4:25.

14. Maitland K, Kiguli S, Opoka RO, Engoru C, Olupot-Olupot P, Akech SO, Nyeko $R$, Mtove $G$, Reyburn $H$, Lang $T$, et al: Mortality after fluid bolus in African children with severe infection. N Engl J Med 2011, 364(26):2483-2495.

15. De Boer HM: "Out of the shadows": a global campaign against epilepsy. Epilepsia 2002, 43(Suppl 6):7-8.

16. Dua T, Barbui C, Clark N, Fleischmann A, Poznyak V, van Ommeren M, Yasamy MT, Ayuso-Mateos JL, Birbeck GL, Drummond C, et al: Evidencebased guidelines for mental, neurological, and substance use disorders in low- and middle-income countries: summary of WHO recommendations. PLoS Med 2011, 8(11):e1001122.

17. Yemadje LP, Houinato D, Quet F, Druet-Cabanac M, Preux PM: Understanding the differences in prevalence of epilepsy in tropical regions. Epilepsia 2011, 52(8):1376-1381.

18. Preux PM, Druet-Cabanac M: Epidemiology and aetiology of epilepsy in sub-Saharan Africa. Lancet Neurol 2005, 4(1):21-31.

19. Radhakrishnan K: Challenges in the management of epilepsy in resourcepoor countries. Nat Rev Neurol 2009, 5(6):323-330.

20. Birbeck GL: Epilepsy care in developing countries: part I of II. Epilepsy Curr 2010, 10(4):75-79.

21. Anand K, Jain S, Paul E, Srivastava A, Sahariah SA, Kapoor SK: Development of a validated clinical case definition of generalized tonic-clonic seizures for use by community-based health care providers. Epilepsia 2005, 46(5):743-750

22. de Bittencourt PR, Adamolekum B, Bharucha N, Carpio A, Cossio OH, Danesi MA, Dumas M, Fernandes JG, Genton P, Manreza ML, et al: Epilepsy in the tropics: Il. Clinical presentations, pathophysiology, immunologic diagnosis, economics, and therapy. Epilepsia 1996, 37(11):1128-1137.

23. Kvalsund MP, Birbeck GL: Epilepsy care challenges in developing countries. Curr Opin Neurol 2012, 25(2):179-186.

24. Birbeck GL, French JA, Perucca E, Simpson DM, Fraimow H, George JM, Okulicz JF, Clifford DB, Hachad H, Levy RH: Evidence-based guideline: Antiepileptic drug selection for people with HIV/AIDS: report of the Quality Standards Subcommittee of the American Academy of Neurology and the Ad Hoc Task Force of the Commission on Therapeutic Strategies of the International League Against Epilepsy. Neurology 2012, 78(2):139-145.

25. Winkler AS, Schaffert M, Schmutzhard E: Epilepsy in resource poor countries-suggestion of an adjusted classification. Epilepsia 2007, 48(5):1029-1030.

26. Birbeck GL: Revising and refining the epilepsy classification system: Priorities from a developing world perspective. Epilepsia 2012, 53(Suppl 2):18-21.

27. Fretheim A, Schunemann HJ, Oxman AD: Improving the use of research evidence in guideline development: 15 . Disseminating and implementing guidelines. Health Res Policy Syst 2006, 4:27.

28. Baskind R, Birbeck G: Epilepsy care in Zambia: a study of traditional healers. Epilepsia 2005, 46(7):1121-1126.

29. Oxman AD, Schunemann HJ, Fretheim A: Improving the use of research evidence in guideline development: 16. Evaluation. Health Res Policy Syst 2006, 4:28

30. Fountain NB, Van Ness PC, Swain-Eng R, Tonn S, Bever CT Jr: Quality improvement in neurology: AAN epilepsy quality measures: Report of the Quality Measurement and Reporting Subcommittee of the American Academy of Neurology. Neurology 2011, 76(1):94-99.

31. Kvalsund M, Mbewe E, Mulenga J, Atadzhanov M, Haworth A, Chomba E, Birbeck G: Quality indicators for epilepsy care in Zambia: Roadwork for the WHO Mental Health Gap Action (mh GAP) program. American Academy of Neurology Annual Meeting 2012 P07116, April 2012 2012; New Orleans 2012 [http://wwwabstracts2viewcom/aan/viewphp? nu=AAN12L_P07_116\&terms].

32. Grilli R, Magrini N, Penna A, Mura G, Liberati A: Practice guidelines developed by specialty societies: the need for a critical appraisal. Lancet 2000, 355(9198):103-106.

33. Shekelle PG, Woolf $S H$, Eccles $M$, Grimshaw J: Clinical guidelines: developing guidelines. Bmj 1999, 318(7183):593-596.

\section{Pre-publication history}

The pre-publication history for this paper can be accessed here: http://www.biomedcentral.com/1741-7015/10/107/prepub

\section{doi:10.1186/1741-7015-10-107}

Cite this article as: Katchanov and Birbeck: Epilepsy care guidelines for low- and middle- income countries: From WHO mental health GAP to national programs. BMC Medicine 2012 10:107.

\section{Submit your next manuscript to BioMed Central and take full advantage of:}

- Convenient online submission

- Thorough peer review

- No space constraints or color figure charges

- Immediate publication on acceptance

- Inclusion in PubMed, CAS, Scopus and Google Scholar

- Research which is freely available for redistribution

Submit your manuscript at www.biomedcentral.com/submit
Ciomed Central 